\title{
Rheological control of oceanic crust separation in the transition zone
}

\author{
P.E. van Keken \\ Department of Geological Sciences, University of Michigan, Ann Arbor
}

\section{S. Karato}

Department of Geology and Geophysics, University of Minnesota, Minneapolis

\section{D.A. Yuen}

Minnesota Supercomputer Institute, University of Minnesota, Minneapolis

\begin{abstract}
Mineral physics observations suggest that distinct density and rheological differences exist between the crustal component of oceanic lithosphere and the underlying mantle. We have conducted numerical experiments to investigate the influence of both density and viscosity on the effectiveness of recycling of oceanic crust into the lower mantle. Confirming previous results, the density inversion at $670 \mathrm{~km}$ depth alone is not sufficient to prevent crustal recycling. However, a soft layer may exist between the strong garnet crust and cold slab interior. Models employing a simplified Newtonian sandwich model show that this thin, weak layer can effectively decouple the crust and slab. Once entrained into the lower mantle, the then lighter crust can rise sufficiently fast as a Rayleigh-Taylor instability to avoid further entrainment. These results suggest that the crustal component of slabs may be trapped at $670 \mathrm{~km}$ depth, leading to a garnet enriched transition zone.
\end{abstract}

\section{Introduction}

Recycling of oceanic crust has large consequences on both the chemical evolution of the Earth's upper mantle and transition zone and the dynamical interpretation of geochemical data. Subducted oceanic crust is transformed into a garnet-rich assembly (garnetite) in the depth range of approximately 400 to at least 800 km [Irifune and Ringwood, 1993; O'Neill and Jeanloz, 1994]. Garnetite is denser than peridotite in the transition zone, but is less dense than perovskite in the lower mantle. A proposed recycling mechanism includes the separation of oceanic crust near the $670-\mathrm{km}$ discontinuity, as a consequence of the neutral buoyancy of the crust in the garnet phase at that depth [Ringwood, 1967, 1994; Anderson, 1979; Ringwood and Irifune, 1988].

In addition to density differences, laboratory deformation experiments give evidence for a strong rheology of garnet compared to that of peridotite [Karato, 1989;

\section{Copyright 1996 by the American Geophysical Union.}

Paper number 96GL01594

0094-8534/96/96GL-01594\$05.00
Karato et al., 1995; Ingrin and Madon, 1995]. This creates a slab rheology with two distinct strong zones of the garnet crust and cold slab interior, separated by a weak and hot peridotite layer. We have studied the influence of both density and rheology variations on the possible crustal separation in the transition zone, using highresolution 2-D finite element models of thermochemical convection.

\section{Model description}

We investigate the possible processes of separation of crustal component from the main component of slabs that are sinking due to the negative buoyancy caused by the higher density of the cool slab interior and to a lesser degree- the higher compositional density of the garnetitic crust. At the bottom of the transition zone only the mantle component of the slab is com-

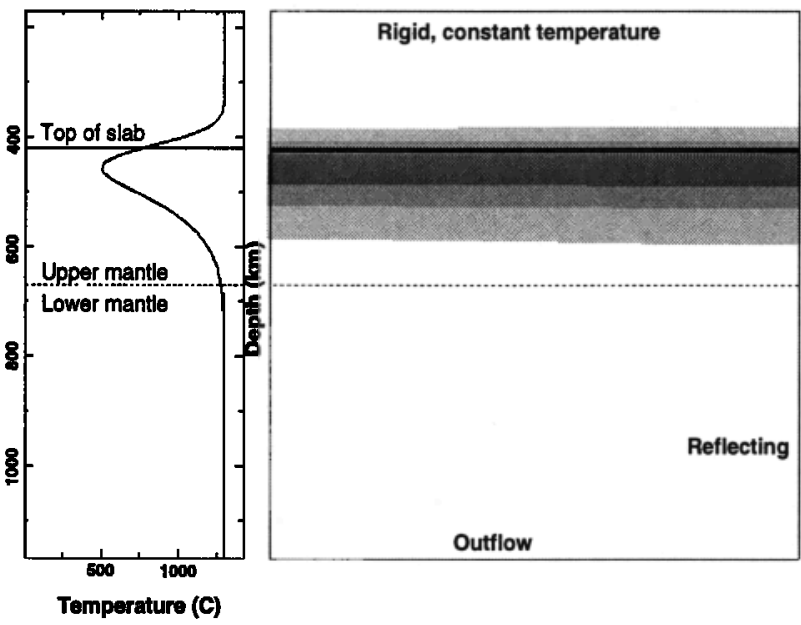

Figure 1. Initial condition and boundary conditions employed in the modeling. A cold slab is placed at $400 \mathrm{~km}$ depth in the upper mantle. The temperature profile (left) is based on an $100 \mathrm{Myr}$ old oceanic lithosphere that has been subducted $10 \mathrm{Myr}$ ago. The computational domain is 1000 by $1000 \mathrm{~km}$ (right) and is modeled with an outflow boundary at the bottom, reflecting boundaries at the sides and a rigid, constant temperature boundary condition at the top. The black solid line indicates the $7 \mathrm{~km}$ thick garnetitic crust. 


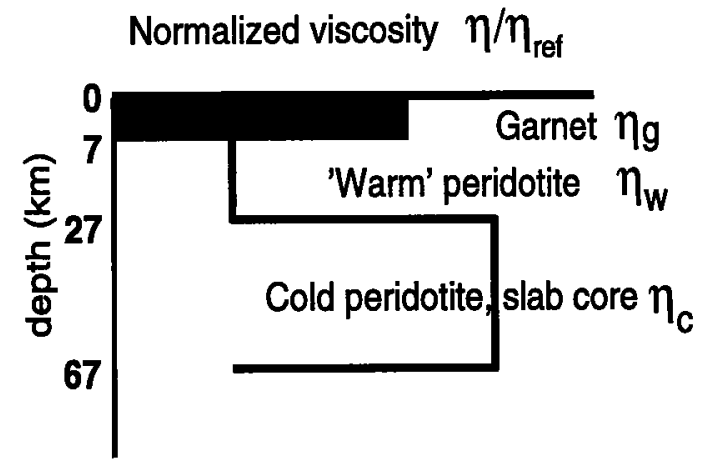

Figure 2. Simplified viscosity profile in the slab. The sandwich type rheology is composed of a compositionally stiff crustal layer and a thermally cold and high viscous slab core, separated by a warm and weaker peridotitic layer.

pressed into the denser perovskite. Below the $670 \mathrm{~km}$ discontinuity the crust will become lighter than the surrounding mantle and will attempt to separate from the sinking slab. The success of crust separation depends on the relative buoyancy forces associated with thermal and compositional variations, the rheological coupling of crust and mantle and the speed of the sinking slab. Because we only wish to study the trade-off between chemical and buoyancy forces in the slab itself, we ignore the effects of the topography of the $670 \mathrm{~km}$ discontinuity, latent heat release, and viscous dissipation.

To model this process of crust separation, we initially insert a layered heavy slab horizontally in the middle upper mantle (Figure 1). The initial temperature profile in the slab is one for an oceanic lithosphere of $100 \mathrm{Myr}$ old that was subducted $10 \mathrm{Myr}$ ago. The top part of the slab (modeled now at $400 \mathrm{~km}$ depth) has warmed up and is now a few hundred degrees warmer than the slab interior. A slab with this temperature profile is inserted horizontally in a box of 1000 by $1000 \mathrm{~km}$ (shown on the right). The grey colors indicate temperature, the black line indicates the $7 \mathrm{~km}$ thick garnetitic crust at the top of the slab.

The rheology of the slab is approximated by a sim- plified sandwich model shown in Figure 2. The mantle surrounding the slab is assumed to be isoviscous at viscosity $\eta_{\text {ref }}$. In the following, all viscosities are non-dimensionalized using this reference viscosity. The crustal layer (viscosity $\eta_{g}$ ) is composed mostly of garnet and is relatively strong although it is warm. The peridotitic slab interior (viscosity $\eta_{c}$ ) is cold and therefore strong. These two high viscosity layers are separated by a warmer and weaker peridotite layer with viscosity $\eta_{w}$. These parameters are treated as free parameters, under the assumption $\eta_{w}<\eta_{g} \leq \eta_{c}$. The thicknesses of the weak layer and the slab core are assumed to be 20 and $40 \mathrm{~km}$ respectively.

Other physical parameters describing the model are thermal expansivity $\left(3 \times 10^{-5} \mathrm{~K}^{-1}\right)$, reference viscosity $\left(\eta_{\text {ref }}=10^{21} \mathrm{~Pa} \cdot \mathrm{s}\right)$ and density contrast between crust and mantle in the upper $\left(0.1 \times 10^{3} \mathrm{~kg} \cdot \mathrm{m}^{-3}\right)$ and lower mantle $\left(-0.2 \times 10^{3} \mathrm{~kg} \cdot \mathrm{m}^{-3}\right)$ [Irifune and Ringwood, 1993].

The mathematical equations describing thermochemical convection under the Boussinesq assumption are well known and are outlined in e.g. Hansen and Yuen [1994]. The equations are solved numerically using the finite element package Sepran [Segal and Praagman, 1995] that has been well tested and applied to a variety of geodynamical problems [e.g., Van Keken et al., 1993; Van den Berg et al., 1993]. A markerchain method is employed to accurately track the compositional and rheological variation in the slab [Christensen and Yuen, 1984; Van Keken et al., 1993]. The positions of the markers are advected using a fourth order RungeKutta scheme to guarantee sufficient accuracy. During the model calculations, markers were inserted to maintain a maximum dimensional marker spacing of $2 \mathrm{~km}$. Local grid refinement is used; in the region where the slab penetrates the average spacing between integration points (where the viscosity is specified) is $2 \mathrm{~km}$.

\section{Results}

The evolution of compositionally stratified slabs sinking through the transition zone has been studied previ-
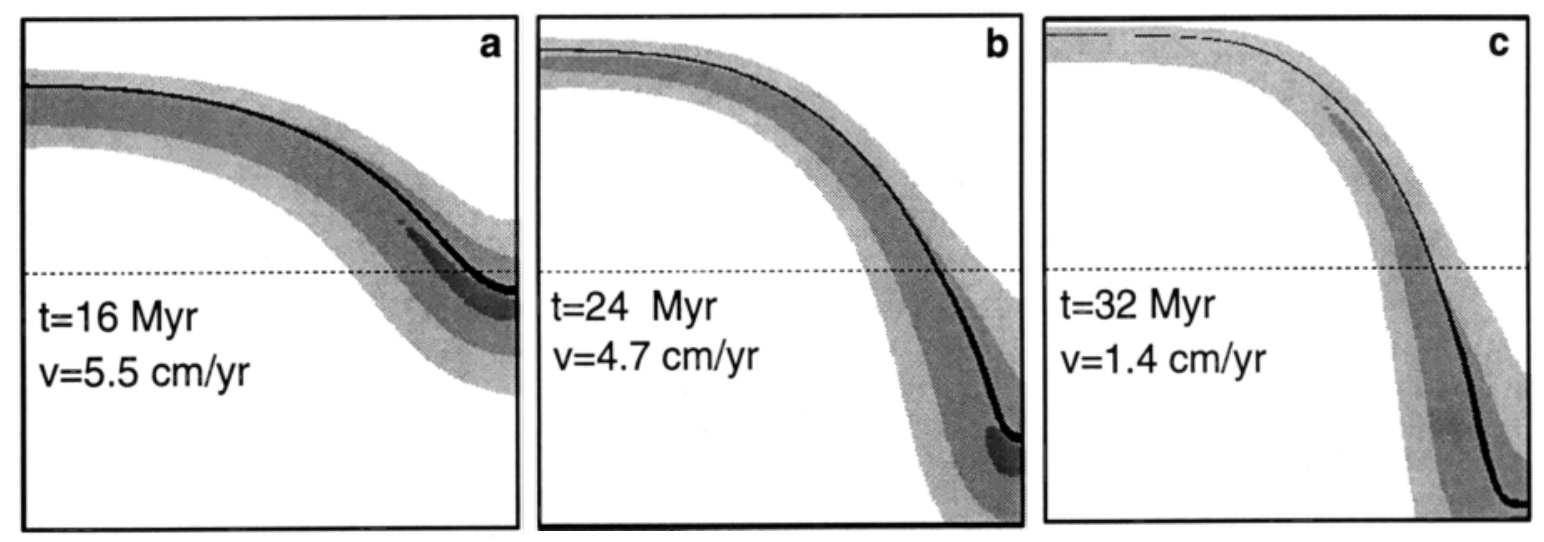

Figure 3. Snapshots of the model evolution for a constant viscosity slab. Dimensional times and maximum vertical velocity are indicated in each frame. Although the garnet becomes compositionally buoyant below 670 $\mathrm{km}$ (indicated by the dashed line), the coupling with the much thicker, colder slab is strong enough to entrain the garnet into the lower mantle. 

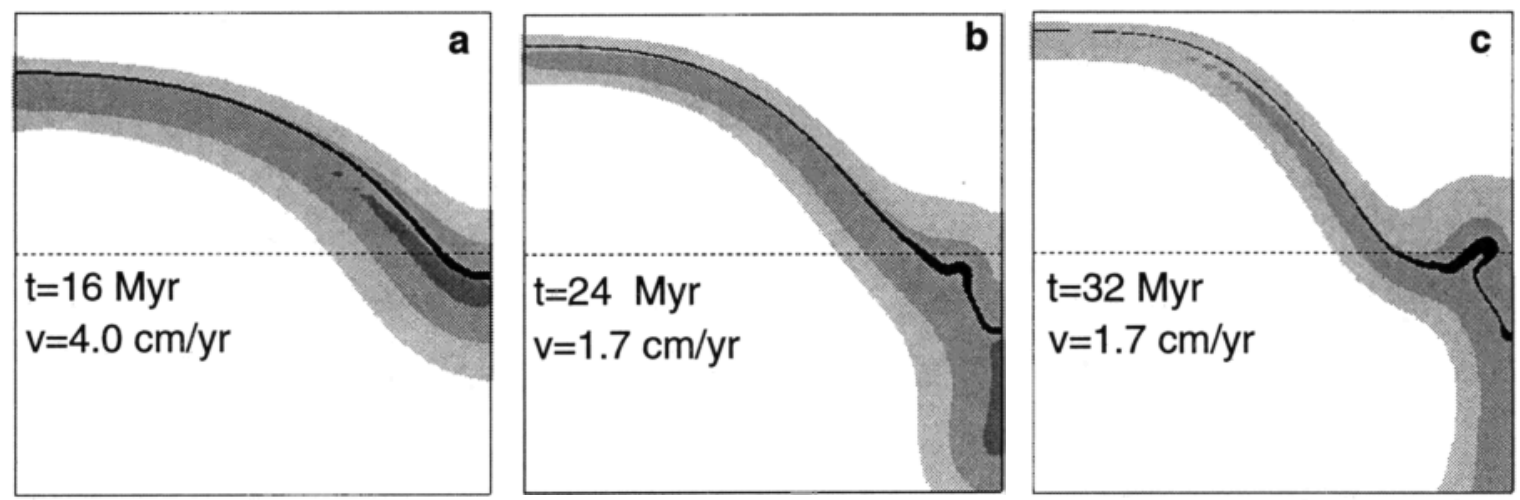

Figure 4. As figure 3, but now for the sandwich rheology (Figure 2) with $\eta_{w}=0.01 \eta_{c}$. The garnet layer is now effectively decoupled and can rise as a Rayleigh-Taylor type instability from the subducting slab, once it is in the lower mantle.

ously by e.g., Gurnis [1986], Richards and Davies [1989] and Gaherty and Hager [1994] under the assumption that the viscosity is constant or only dependent on temperature. The evolution of a similar model is shown in Figure 3, where $\eta_{g}=\eta_{w}=\eta_{c}=10$. Dimensional time and maximum vertical velocity of the slab are indicated in the frames. In this case, the coupling between crust and mantle is sufficiently strong to entrain the crust into the lower mantle. The positive compositional buoyancy force of the crust is not sufficient to overcome the drag of thicker, cold slab. Note that the maximum vertical velocity is more than $5 \mathrm{~cm} / \mathrm{yr}$, which is near the high end of vertical slab velocities than can be expected based on present-day plate velocities.

The evolution is distinctly different if the rheological stratification due to the combined thermal and compositional effect is taken into account. Figure 4 shows the slab at the same times as in Figure 3, but now with $\eta_{g}=\eta_{c}, \eta_{w}=0.01 \eta_{g}$. The crust that becomes buoyant in the lower mantle is now less strongly coupled to the underlying sinking slab and the garnet can separate from the colder parts of the slab.

We have conducted a variety of experiments to test the sensitivity of this conclusion to values of the viscosity parameters $\eta_{c}, \eta_{w}$, and $\eta_{g}$. Figure 5 presents some results obtained by varying $\eta_{w}$, but keeping the other parameters constant. As can be expected, crustal delamination becomes more efficient with decreasing strength of the decoupling zone. Although some crust may be entrained in the lower mantle, a large part of the crust rises back into the transition zone if $\eta_{g}<0.1 \eta_{c}$. This viscosity contrast is not too unreasonable, taking into account that the top of the slab is a few hundred degrees hotter than the core of the slab (Figure 1). In addition, the effects of superplasticity [Sammis and Dein, 1974], that are expected to take place at 670 in the peridotite but not in the garnetite, will effectively lower $\eta_{w}$

\section{Discussion}

The results confirm previous modeling results that crust-mantle separation cannot take place if the crust is strongly coupled to the subducting slab. If a thin viscous decoupling zone is modeled between crust and cold slab interior, the crust can separate through a RayleighTaylor type instability in the lower mantle. However, under the assumption of this sandwich type rheology, the crustal component of a subducting slab can separate from the down-going slab. This conclusion is simi-
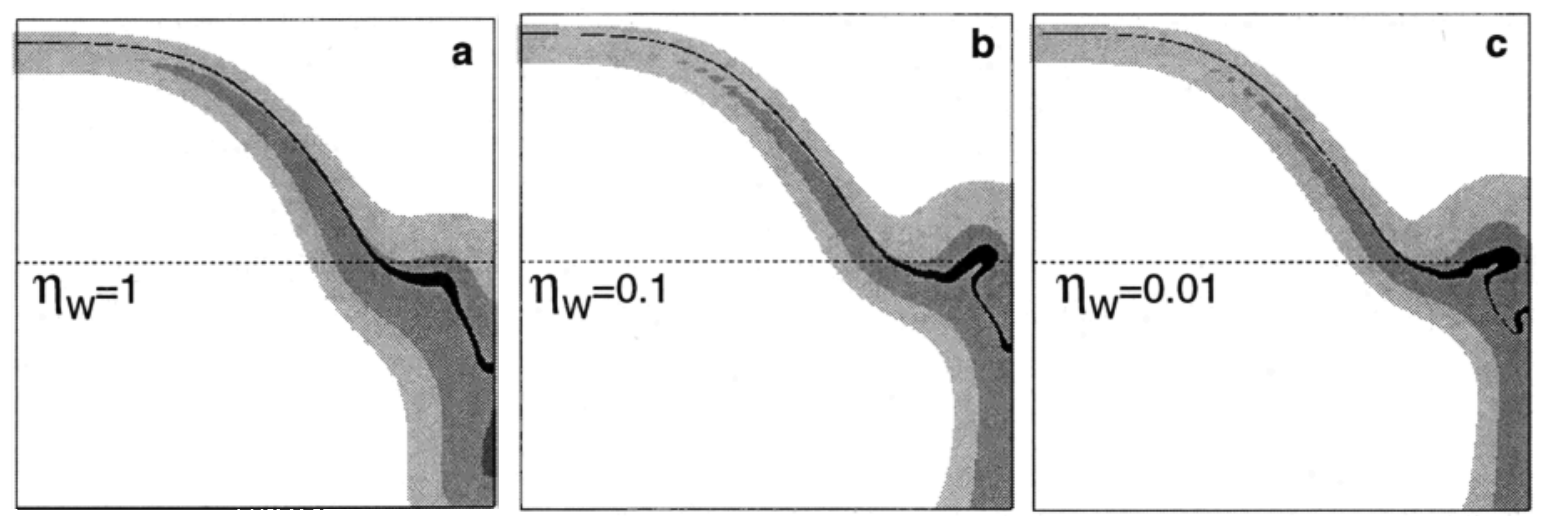

Figure 5. Comparison of model results for different values of the viscosity of the weak layer $\eta_{w}$. Frame b) is the last frame of Figure 4. Even at relatively low viscosity contrasts, a large part of the crust can separate from the sinking slab. 
lar to that obtained by Karato [1995] although he used different assumptions about the geometry of the slab separation.

The results presented in this study warrant a more elaborate study that would take into account i) a more realistic viscosity description that incorporates temperature- and stress-dependence explicitly; ii) the influence of the phase change at $670 \mathrm{~km}$ as expressed in phase boundary topography and latent heat exchange; iii) the effects of shear heating, in particular in combination with the feedback influence for temperaturedependent rheology [Steinbach and Yuen, 1995]. The viscosity contrasts that are used in this paper are at the lower end of a range that would be appropriate for upper mantle silicates with high activation energy (of around $500 \mathrm{~kJ} / \mathrm{mole}$ ). It can be expected that the warming of the slab during descent will strongly decrease the viscosity of both the slab interior and the garnetitic crust. However, the layered viscosity structure will not be modified strongly, but the separation process may take place faster than modeled here.

The evidence for crustal separation at the top of the lower mantle as found in this study indicates that lower parts of the transition zone may be predominantly composed of garnet, which has both a high intrinsic viscosity and a strong temperature dependence. This combination can provide a tentative explanation for the fixity of the source of hot spot volcanism originating from the transition zone [e.g., Allegre and Turcotte, 1985].

Acknowledgments. We thank Ulrich Christensen, Peter Olson, and Geoff Davies for discussions. Arie van den Berg, Tetsuo Irifune and an anonymous referee are thanked for their constructive reviews.

\section{References}

Allegre, C.J. and D.L. Turcotte, Geodynamic mixing in the mesosphere boundary layer and the origin of oceanic islands, Geophys. Res. Lett., 12, 207-210, 1985.

Anderson, D.L., Chemical stratification of the mantle, $J$. Geophys. Res., 84, 6297-6298, 1979.

Christensen, U.R., and D.A. Yuen, The interaction of a subducting lithospheric slab with a chemical or phase boundary. J. Geophys. Res., 89, 4389-4402, 1984.

Gaherty, J.B., and B.H. Hager, Compositional vs. thermal buoyancy and the evolution of subducted lithosphere. Geophys. Res. Lett., 21, 141-144, 1994.

Gurnis, M., The effects of chemical density differences on convective mixing in the earth's mantle, J. Geophys. Res., $95,397-419,1986$.

Hansen, U., and D.A. Yuen, Effects of depth-dependent thermal expansivity on the interaction of thermalchemical plumes with a compositional boundary, Phys. Earth Planet. Inter., 86, 205-221, 1994.

Ingrin, J., and M. Madon, TEM observations of several spinel-garnet assemblies: toward the rheology of the transition zone, Terra Nova, 7, 509-515, 1995.

Irifune, T., and A.E. Ringwood, Phase transformation in subducted oceanic crust and buoyancy relationships at depths of $600-800 \mathrm{~km}$ in the mantle, Earth Planet. Science Lett., 117, 101-110, 1993.

Karato, S., Plasticity-crystal structure systematics in dense oxides and its implications for the creep strength of the Earth's deep interior, Phys. Earth Planet. Inter., 56, 234-240, 1989.

Karato, S., Interaction of chemically stratified subducted oceanic lithosphere with the $660 \mathrm{~km}$ discontinuity, Proc.Japan Acad., 71B, 203-207, 1995.

Karato, S., Z. Wang, B. Liu and K. Fujino, Plastic deformation of garnets and its bearing on the dynamics and chemical evolution of the transition zone, Earth Planet. Science Lett., 130, 13-30, 1995.

O'Neill, B., and R. Jeanloz, $\mathrm{MgSiO}_{3}-\mathrm{FeSiO}_{3}-\mathrm{Al}_{2} \mathrm{O}_{3}$ in the Earth's lower mantle: Perovskite and garnet at $1200 \mathrm{~km}$ depth, J. Geophys. Res., 99, 19901-19915, 1994.

Richards, M.A., and G.F. Davies, On the separation of relatively buoyant components from subducted lithosphere, Geophys. Res. Lett., 16, 831-834, 1989.

Ringwood, A.E., The pyroxene-garnet transformation in the Earth's mantle, Earth Planet. Science Lett., 2, 255-263, 1967.

Ringwood, A.E., Role of the transition zone and $660 \mathrm{~km}$ discontinuity in mantle dynamics. Phys. Earth Planet. Inter., 86, 5-24, 1994.

Ringwood, A.E., and T. Irifune, Nature of the $650-\mathrm{km}$ seismic discontinuity, Nature, 331, 131-136, 1988.

Sammis, C.G., and J.L. Dein, On the possibility of transformational superplasticity in the Earth's mantle, J. Geophys. Res., 79, 2961-2965, 1974.

Segal, G. and N.P. Praagman, Sepran user's guide, SEPRA, Technical University Delft, The Netherlands, 1995.

Steinbach, V., and D.A. Yuen, The effects of temperaturedependent viscosity on mantle convection with the two major phase transitions, Phys. Earth Planet. Inter., 90, 13-36, 1995.

Van Keken, P.E., C.J. Spiers, A.P. van den Berg, and E.J. Muyzert, The effective viscosity of rocksalt: implementation of steady-state creep laws in numerical models of salt diapirism, Tectonophysics, 225, 457-476, 1993.

Van den Berg, A.P., P.E. van Keken and D.A. Yuen, The effects of a composite non-Newtonian and Newtonian rheology on mantle convection. Geophys. J. Int., 115, 62-78, 1993.

S. Karato, Department of Geology and Geophysics, University of Minnesota, 108 Pillsbury Hall, Minneapolis, MN 55455, karato@maroon.tc.umn.edu .

P.E. van Keken, Department of Geological Sciences, University of Michigan, 2534 CC Little Building, Ann Arbor, MI 48109, keken@umich.edu .

D.A. Yuen, Minnesota Supercomputer Institute, University of Minnesota, 1200 Washington Ave S., Minneapolis, MN 55415, davey@krissy.msi.umn.edu .

(received February 15, 1996;

accepted March 25, 1996.) 